\title{
Knockdown of anti-silencing function 1B histone chaperone induces cell apoptosis via repressing PI3K/Akt pathway in prostate cancer
}

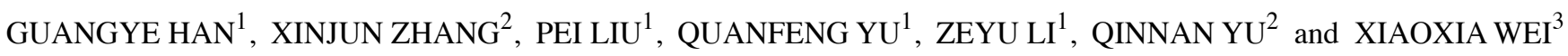 \\ ${ }^{1}$ The Second Ward of Urology Department, ${ }^{2}$ The First Ward of Urology Department and \\ ${ }^{3}$ The Second Ward of Infection Department, The First Affiliated Hospital of \\ Xinxiang Medical University, Xinxiang, Henan 453100, P.R. China
}

Received April 9, 2018; Accepted August 9, 2018

DOI: $10.3892 /$ ijo.2018.4526

\begin{abstract}
Prostate cancer (PCa) is one of the most common malignancies among males worldwide. Anti-silencing function 1B histone chaperone (ASF1B) has been reported to be involved in $\mathrm{PCa}$. The present study aimed to investigate the role and molecular mechanism of ASF1B in PCa. Data of genes were obtained from The Cancer Genome Atlas database. The core gene was identified using the DAVID website. Cell viability and colony formation were detected using a cell counting kit-8 assay and crystal violet staining, respectively. Cell cycle distribution and apoptosis were assessed using flow cytometry analysis. The corresponding factors were analyzed by reverse transcription-quantitative polymerase chain reaction and western blotting. It was demonstrated that ASF1B was highly expressed in the PCa tissues and cells compared with the non-PCa tissues and cells, respectively. While siRNA-ASF1B significantly reduced the viability and colony formation, it promoted apoptosis, G1 phase cell cycle arrest of LNCap as well as C4-2 cells. siRNA-ASF1B was revealed to significantly reduce the level of B-cell lymphoma-2 and cyclin D1, and enhance the expression levels of p53, caspase- 3 and Bcl-2 associated X protein. Furthermore, the phosphorylation levels of phosphatidylinositol 3 kinase (PI3K) and protein kinase $\mathrm{B}$ (Akt) were significantly decreased in the siRNA-ASF1B group compared with the mock group. In summary, the present study demonstrated that silencing of ASF1B suppressed the proliferation, and promoted apoptosis
\end{abstract}

Correspondence to: Professor Guangye Han, The Second Ward of Urology Department, The First Affiliated Hospital of Xinxiang Medical University, 88 Jiankang Road, Weihui, Xinxiang, Henan 453100, P.R. China

E-mail: guangyehan_hgy@163.com

Key words: anti-silencing function 1B histone chaperone, prostate cancer, apoptosis, phosphatidylinositol 3 kinase/protein kinase B pathway and cell cycle arrest of PCa cells. Inhibition of the PI3K/Akt signaling pathway was pertinent to the role of si-ASF1B. This phenomenon suggests that the downregulation of ASF1B may aid in inhibiting the progression of $\mathrm{PCa}$.

\section{Introduction}

Prostate cancer ( $\mathrm{PCa}$ ) is one of the most common malignancies among males worldwide $(1,2)$. The incidence of PCa has continued to rise in developed countries in recent years (3-5). To the best of our knowledge, no clinical symptoms are observable in the early stage of the cancer, and therefore a majority of patients are diagnosed with $\mathrm{PCa}$ in its advanced stage. The primary treatment methods of PCa are surgery, radiotherapy, cryosurgery, chemotherapy and endocrinotherapy. However, the effects of these treatments are not satisfactory, with the 5 -year survival rate of patients with distant metastasis in the United States remaining $20 \%(4,6-8)$. Therefore, it is necessary to identify a safe and effective strategy for treating $\mathrm{PCa}$.

Cancer is known to be a genotypic disease, and therefore the occurrence of cancer is associated with changes to gene expression (9-11). In recent years, researchers have investigated target genes of cancer, and suggest that targeting therapy may be used to slow down the progression of cancer (12-15). Several studies have demonstrated that various genes, including melanoma differentiation associated gene-9/syntenin, sirtuin 1 and lysine demethylase $1 \mathrm{~A}$, contribute to the growth, metastasis and differentiation of PCa (16-19). Thus, determining target genes associated with the progression of $\mathrm{PCa}$ is required.

The phosphatidylinositol 3 kinase (PI3K)/protein kinase $\mathrm{B}$ (Akt/PKB) signaling pathway is widely distributed in cells, and contributes to the regulation of cell growth, proliferation and differentiation (20,21). Furthermore, the PI3K/Akt signal transduction pathway serves an essential role in the occurrence, development, treatment and prognosis of malignant tumor $(22,23)$. PI3K, a bridge molecule associated with extracellular signal and cellular responses, serves an essential role in regulating cell apoptosis. Akt is a type of serine/threonine protein kinase. When cells are stimulated by extracellular signals, PI3K activates Akt activity and Akt further activates its downstream factors (24-26). 
The present study aimed to explore the genes associated with the survival time of patients with PCa. Anti-silencing function 1B histone chaperone (ASF1B) was selected as a potential molecular involved in $\mathrm{PCa}$ and role was investigated. Thus, data from healthy adjacent and PCa tissues were collected from the Cancer Genome Atlas (TCGA) database. The differential genes among cancer and healthy adjacent tissues were analyzed using the edgeR software package. The core gene was identified using the DAVID website.

\section{Materials and methods}

Selection of core gene and determination of gene function. The genes in 499 PCa and 52 adjacent healthy tissues from the TCGA database were analyzed using the edgeR software package (http://www.bioconductor.org/packages/release/bioc/ html/edgeR.html). Next, 156 genes identified to be significantly associated with the survival of the patients were screened. The selected 156 genes were analyzed using the DAVID available online database (https://david.ncifcrf.gov/). The functions of the top seven core genes on the cell were investigated using Gene Ontology (GO) analysis (http://www.geneontology.org/). ASF1B was selected for subsequent experiments.

Tissue source. Between June 2015 and September 2017, 37 samples of PCa tissues and healthy adjacent tissues (mean age, $65.5 \pm 7$ years) were obtained from patients with $\mathrm{PCa}$ who were admitted to The First Affiliated Hospital of Xinxiang Medical University (Xinxiang, China). Patients were diagnosed with PCa by biopsy or pathology. Patients who also had other malignant tumors, coronary heart disease or diabetes were excluded. All patients signed informed consent for the use of their tissues in the present study. This research was approved by the Ethics Committee of The First Affiliated Hospital of Xinxiang Medical University.

Cell culture. Human prostatic hyperplasia epithelial cell line (BPH) and PCa cell lines (PC-3, DU145, LNCap, VcaP and C4-2) were purchased from Beijing Zeping Technology Co., Ltd. (Beijing, China). PC-3 is derived from a bone metastatic site, and LNCap is derived from a left supraclavicular lymph node metastatic site. As a subline of LNCap, C4-2 exhibits androgenindependent growth in association with skeletal metastasis. DU145 is derived from a brain metastatic site and VcaP is derived from a vertebra metastatic site. BPH cells were cultured in Dulbecco's modified Eagle's medium (DMEM; Beijing Solarbio Science \& Technology Co., Ltd., Beijing, China) with $10 \%$ fetal bovine serum (FBS; Thermo Fisher Scientific, Inc., Waltham, MA, USA) and penicillin-streptomycin mixed solution. PC-3, DU145, LNCap, VcaP and C4-2 cells were cultured in RPMI-1640 (Beijing Solarbio Science \& Technology Co., Ltd., Beijing, China) with 10\% FBS and 100X penicillin-streptomycin mixed solution. All cells were maintained in a humidified incubator with $5 \% \mathrm{CO}_{2}$ at $37^{\circ} \mathrm{C}$.

RNA interference and transfection. The human anti-silencing function 1 (ASF1)B-target small interfering (si)RNA and unspecific scrambled siRNA vectors were designed and synthesized by Nanjing Kehao Biotechnology Co., Ltd. (Nanjing, China). LNCap and C4-2 cells were seeded at a density of
Table I. Sequences of the primers.

\begin{tabular}{|c|c|c|}
\hline Primer name & Sequence $\left(5^{\prime}-3^{\prime}\right)$ & $\begin{array}{l}\text { Product } \\
\text { size (bp) }\end{array}$ \\
\hline ASF1B & & 231 \\
\hline Forward & GATCAGCTTCGAGTGCAGTG & \\
\hline Reverse & TGGTAGGTGCAGGTGATGAG & \\
\hline p53 & & 246 \\
\hline Forward & GCСССТССТCAGCATCTTAT & \\
\hline Reverse & AAAGCTGTTCCGTCCCAGTA & \\
\hline Cyclin D1 & & 210 \\
\hline Forward & CCCTCGGTGTCCTACTTCAA & \\
\hline Reverse & CTTAGAGGCCACGAACATGC & \\
\hline Bax & & 208 \\
\hline Forward & AACATGGAGCTGCAGAGGAT & \\
\hline Reverse & CCAATGTCCAGCCCATGATG & \\
\hline $\mathrm{Bcl}-2$ & & 207 \\
\hline Forward & TTCTTTGAGTTCGGTGGGGT & \\
\hline Reverse & CTTCAGAGACAGCCAGGAGA & \\
\hline Caspase-3 & & 220 \\
\hline Forward & TGAGCCATGGTGAAGAAGGA & \\
\hline Reverse & TCGGCCTCCACTGGTATTTT & \\
\hline GAPDH & & 222 \\
\hline Forward & CCATCTTCCAGGAGCGAGAT & \\
\hline Reverse & TGCTGATGATCTTGAGGCTG & \\
\hline
\end{tabular}

ASF1B, anti-silencing function 1B histone chaperone; Bcl-2, B-cell lymphoma 2; Bax, Bcl-2-associated $\mathrm{X}$ protein.

$1 \times 10^{4}$ cells/well into 6 -well plates. The cells were transfected with siRNA-ASF1B $(1 \mu \mathrm{g})$ or siRNA-negative control vector $(1 \mu \mathrm{g})$ using Hieff Trans ${ }^{\mathrm{TM}}$ Liposomal Transfection reagent (Shanghai Yusheng Biotechnology Co., Ltd., Shanghai, China) following the manufacturer's protocol. The cells were incubated at $37^{\circ} \mathrm{C}$ for $12 \mathrm{~h}$. Next, the cells were collected and prepared for the subsequent experiments.

Reverse transcription-quantitative polymerase chain reaction $(R T-q P C R)$. Tissues and cells of total RNA were extracted using RNA extraction kit (Promega Corporation, Madison, WI, USA). A total of $1 \mu \mathrm{g}$ of RNA was transcribed to cDNA using TianScript cDNA Synthesis kit (Tiangen Biotech Co., Ltd., Beijing, China). Reaction conditions were as follows: $85^{\circ} \mathrm{C}$ for $5 \mathrm{~min}$, and at $4^{\circ} \mathrm{C}$ for $5 \mathrm{~min}$. SYBR ${ }^{\circledR}$ Premix Ex $\mathrm{Taq}^{\mathrm{TM}}$ II kit (Takara, Beijing, China) was used to amplify cDNA under reaction conditions as follows: Predegeneration at $92^{\circ} \mathrm{C}$ for $5 \mathrm{~min}$; denaturation at $92^{\circ} \mathrm{C}$ for $15 \mathrm{sec}$; annealing at $58^{\circ} \mathrm{C}$ for $30 \mathrm{sec}$ for 30 cycles; and extension at $72^{\circ} \mathrm{C}$ for $35 \mathrm{sec}$. GAPDH was used as the loading control. The $2^{-\Delta \Delta \mathrm{Cq}}$ method was applied to compare gene expression levels. The primers used are listed in Table I.

Western blotting. The proteins of tissues and cells were collected using RIPA lysate buffer (Beijing Solarbio 
Table II. Antibodies used in the present study.

\begin{tabular}{|c|c|c|c|c|}
\hline Antibody & Catalog number & Company & Host animal & Dilution \\
\hline Anti-ASF1B & ab70126 & $\mathrm{Abcam}^{\mathrm{a}}$ & Rabbit & $1: 800$ \\
\hline Anti-p53 & AF1335 & R\&D Systems, Inc..$^{b}$ & Goat & $1: 600$ \\
\hline Anti-cyclin D1 & AF4196 & R\&D Systems, Inc. & Goat & $1: 500$ \\
\hline Anti-caspase-3 & MAB835 & R\&D Systems, Inc. & Rabbit & $1: 500$ \\
\hline Anti- Bcl-2 & 2872 & Cell Signaling Technology, Inc..$^{c}$ & Rabbit & $1: 1,000$ \\
\hline Anti-Bax & 2772 & Cell Signaling Technology, Inc. & Rabbit & $1: 1,000$ \\
\hline Anti-p-PI3K & ab182651 & Abcam & Rabbit & $1: 600$ \\
\hline Anti-PI3K & ab191606 & Abcam & Rabbit & $1: 800$ \\
\hline Anti-p-Akt & AF887 & R\&D Systems, Inc. & Rabbit & $1: 1,000$ \\
\hline Anti-Akt & MAB2055 & R\&D Systems, Inc. & Mouse & $1: 1,000$ \\
\hline Anti-GAPDH & 2275-PC-100 & R\&D Systems, Inc. & Rabbit & $1: 1,000$ \\
\hline
\end{tabular}

${ }^{\mathrm{a} C}$ Cambridge, UK; ${ }^{\mathrm{b}}$ Minneapolis, MN, USA; 'Danvers, MA, USA. ASF1B, anti-silencing function 1B histone chaperone; Bax, Bcl-2-associated $\mathrm{X}$ protein; Bcl-2, B-cell lymphoma 2; PI3K, phosphatidylinositol 3 kinase; Akt, Protein kinase B.

Science \& Technology Co., Ltd.). Protein concentration was detected using a bicinchoninic acid assay. Proteins $(25 \mu \mathrm{g} / \mathrm{lane})$ were separated using $8 \%$ SDS-PAGE and were then transferred onto a polyvinylidene fluoride membrane. The membrane was blocked with $5 \%$ skimmed milk at room temperature $1.5 \mathrm{~h}$. Next, the membrane was incubated with the primary antibodies (Table II) at $4^{\circ} \mathrm{C}$ for $24 \mathrm{~h}$. The membrane was then bound to the donkey anti-mouse $\mathrm{IgG}$ (cat. no. ab150109; 1:6,000), goat anti-mouse IgG (cat. no. ab6785; 1:6,000) (both from Abcam, Cambridge, UK) and donkey anti-rabbit IgG (cat. no. NL004; 1:5,000; R\&D Systems, Inc., Minneapolis, MN, USA) secondary antibodies at $37^{\circ} \mathrm{C}$ for $1 \mathrm{~h}$. The signal was visualized using enhanced chemiluminescence (Sangon Biotech Co., Ltd., Shanghai, China). Quantity One 4.6.2 software (Bio-Rad Laboratories, Inc., Hercules, CA, USA) was used to perform densitometry.

Cell counting kit-8 (CCK-8) analysis. Cell viability was examined using a CCK-8 kit (Beijing Solarbio Science \& Technology Co., Ltd.) following the manufacturer's protocol. In brief, LNCap and C4-2 cells were plated in 96-well plates $\left(1.5 \times 10^{3} \mathrm{cell} / \mathrm{well}\right)$ in an incubator for $24 \mathrm{~h}$. Cells were exposed to PBS (control), unspecific scrambled siRNA plasmid (mock) and ASF1B-target siRNA (siRNA-ASF1B) for 12, 24 and $48 \mathrm{~h}$. Next, CCK- 8 solution was added to the cells and incubated for $4 \mathrm{~h}$. Absorbance at $450 \mathrm{~nm}$ was recorded and evaluated using a microplate reader.

Flow cytometry analysis. Cell apoptosis was examined using an Annexin V-fluorescein isothiocyanate (FITC)/propidium iodide (PI) apoptosis detection kit (Sigma-Aldrich; Merck KGaA, Darmstadt, Germany). LNCap and C4-2 cells were inoculated in 6 -well plates $\left(3 \times 10^{4}\right.$ cells/well $)$ in the incubator for $24 \mathrm{~h}$. All cells were treated as aforementioned. Next, cells were digested by $0.25 \%$ trypsin for 2 min at room temperature. The trypsin was discarded and cells were re-suspended in Annexin V binding buffer. The Annexin V-FITC and PI were added to cells and incubated for $20 \mathrm{~min}$ in the dark at room temperature. BD FACSAria I/II flow cytometry was performed to measure cell apoptosis and analysis was performed using BD CellQuest Pro 3.3 software (both from BD Biosciences, San Jose, CA, USA).

Cell cycle analysis was performed using a PI dye kit (Beyotime Institute of Biotechnology, Shanghai, China) following the manufacturer's protocol. Briefly, LNCap and C4-2 cells were treated as aforementioned. The PI and RNAse mix was added to the cells in the dark at $37^{\circ} \mathrm{C}$ for $20 \mathrm{~min}$. Cell cycle was analyzed using flow cytometry.

Colony formation analysis. The colony formation of cells was determined using crystal violet staining (Beijing Solarbio Science \& Technology Co., Ltd.). Briefly, LNCap and C4-2 cells were inoculated in 6 -well plates $\left(3 \times 10^{4}\right.$ cell/well) and incubated for $24 \mathrm{~h}$. All cells were treated as aforementioned. Cells were then fixed with $100 \%$ methanol for $10 \mathrm{~min}$ at room temperature. Next, cells were stained by $0.1 \%$ crystal violet for $5 \mathrm{~min}$ at room temperature. Finally, the cell colonies were observed under an inverted microscope (IX73; Olympus Corporation, Tokyo, Japan; magnification, x2.5). The number of the colonies containing $>50$ cells was counted to calculate the colony formation as follows: (Number of colonies/number of cells) $\mathrm{x} 100 \%$.

Statistical analysis. IBM SPSS Statistics 20.0 software (IBM, Corp., Armonk, NY, USA) was used for statistical analysis. Data are presented as the mean \pm standard deviation. One-way analysis of variance followed by Tukey's text was performed to compare the differences among groups. The differences between tumor and healthy adjacent tissues were calculated using a paired Student's t-test. Kaplan Meier survival analysis with a log-rank test was performed to compare the overall survival rate of patients grouped by high and low ASF1B expression. The association between the expression of ASF1B and the clinicopathological features of patients with $\mathrm{PCa}$ were assessed using the Chi-square test. $\mathrm{P}<0.05$ was considered to indicate a statistically significant difference. The experiments were independently repeated at least three times. 
A
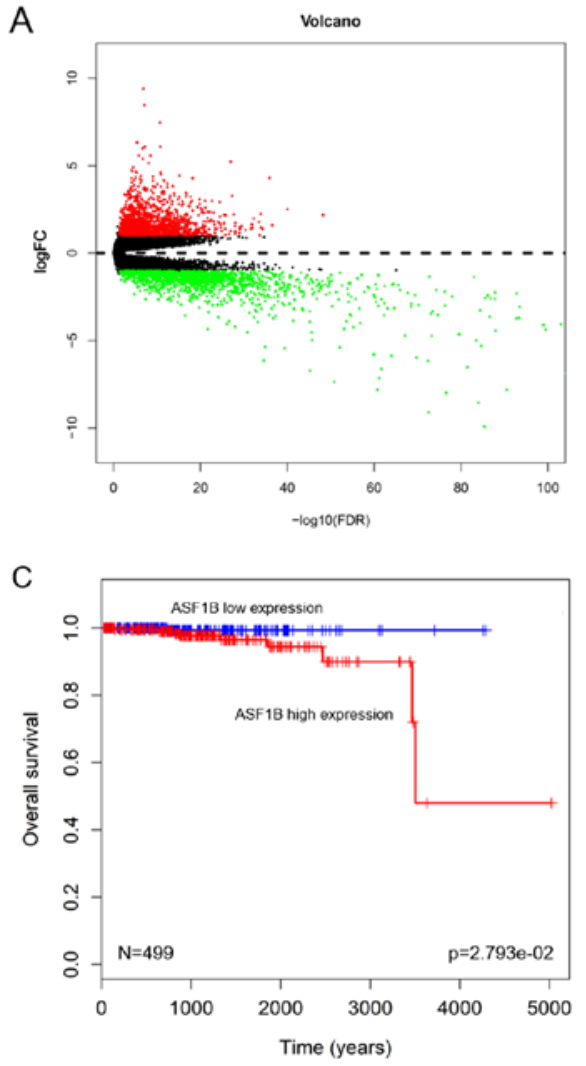

B

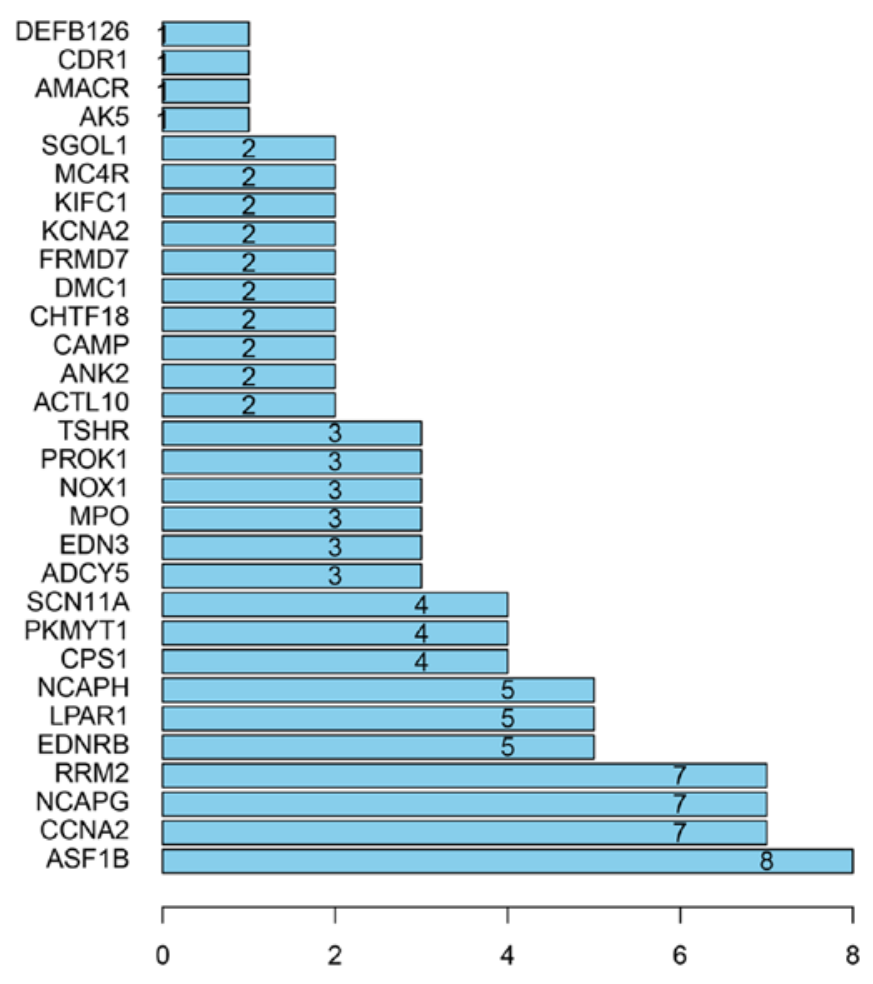

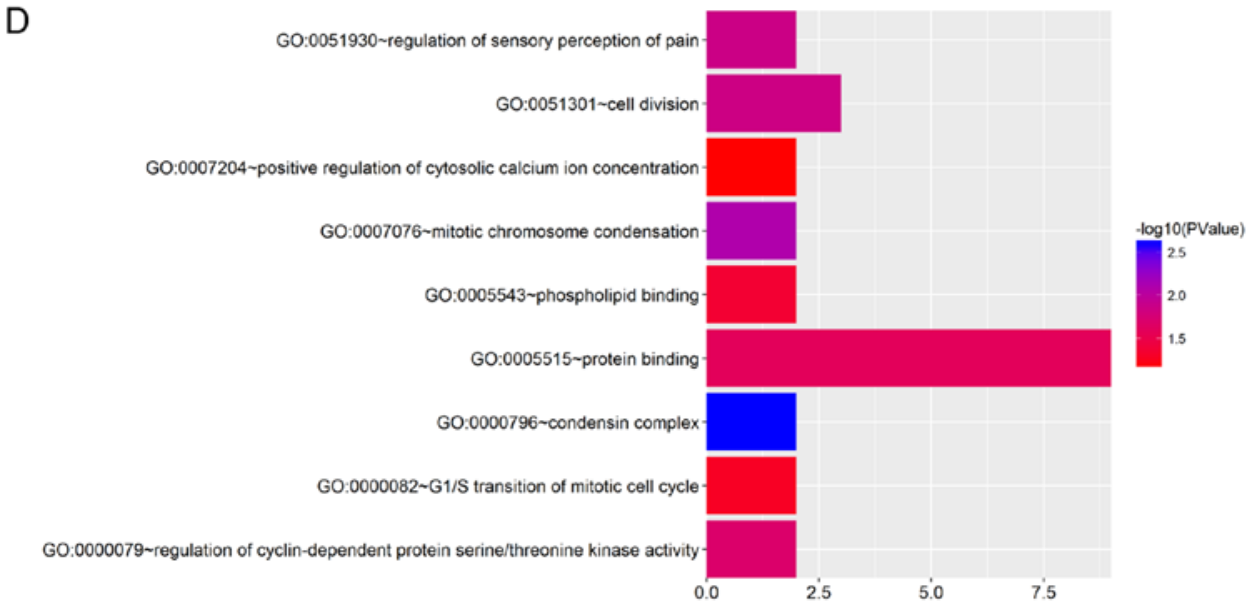

Figure 1. ASF1B is identified as the core gene. (A) The gene with differential expression in 52 healthy adjacent tissues and 499 prostate cancer tissues from the TCGA database was analyzed using the edgeR software package. (B) A total of 156 genes with differential expression were identified to be significantly associated with survival time through analysis using DAVID. The association with ASF1B was the most evident. (C) The overall survival curve of PCa patients with high or low ASF1B expression. (D) The function of ASF1B was investigated using GO analysis (DAVID website). ASF1B, anti-silencing function 1B histone chaperone; FC, fold change; FDR, false discovery rate; TCGA, The Cancer Genome Atlas; GO, Gene Ontology.

\section{Results}

ASF1B is identified as the core gene. To identify the core gene, data from 52 healthy adjacent tissues and $499 \mathrm{PCa}$ tissues were collected from the TCGA database. A total of 2,971 genes were investigated (Fig. 1A) and 156 genes were identified to be significantly associated with the survival rate of patients with PCa (Fig. 1B). A high expression of ASF1B was associated with the poor prognosis of patients with $\mathrm{PCa}$ (Fig. 1C). In addition, GO analysis demonstrated that seven core genes in PCa were significantly associated with cell cycle distribution and cell differentiation (Fig. 1D), the ASF1B gene was selected as the core gene in the present study. To determine the role of the expression of ASF1B in PCa, the pathological features of patients with $\mathrm{PCa}$ were analyzed. The data demonstrated the high ASF1B expression was significantly associated with tumor node metastasis (TNM) stage and metastasis; however, no significant association was identified between ASF1B expression and other pathological features (Table III; P>0.05).

ASF1B is highly expressed in the PCa tissues and cells. RT-qPCR and western blotting were performed in order to examine the expression of ASF1B in the PCa and healthy adjacent tissues. It was demonstrated that the mRNA expression of 
A

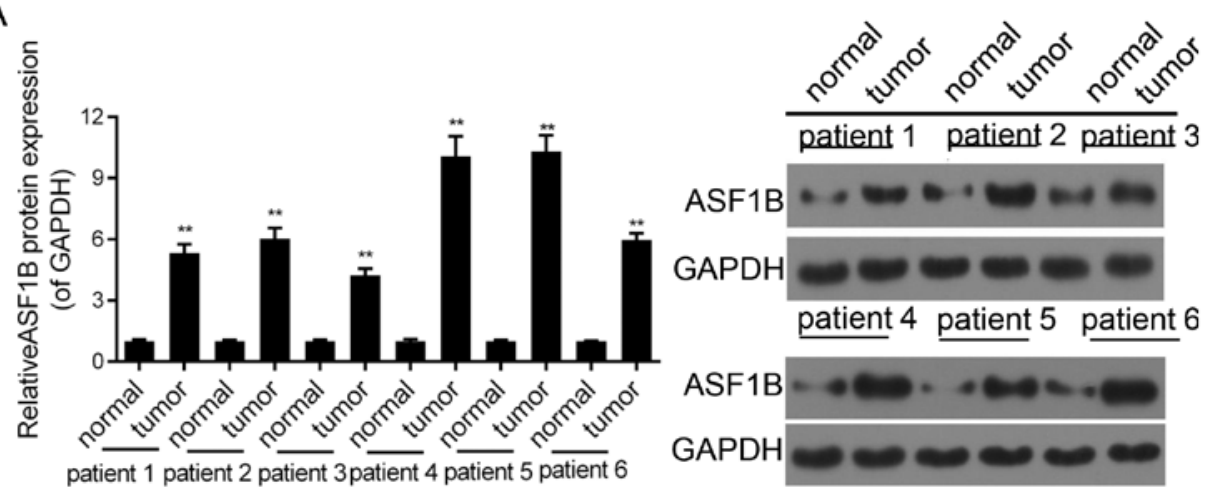

B

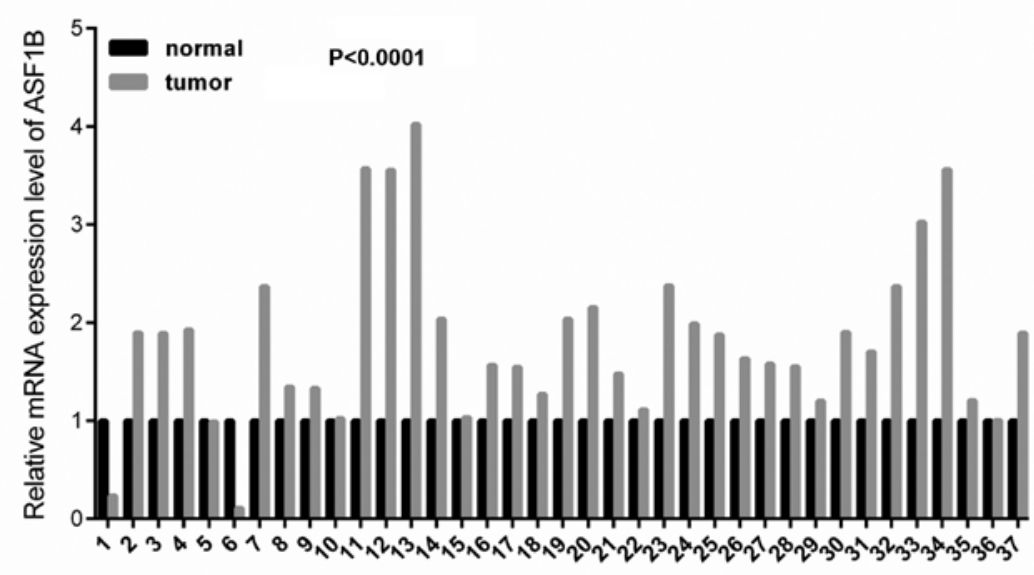

$\mathrm{C}$

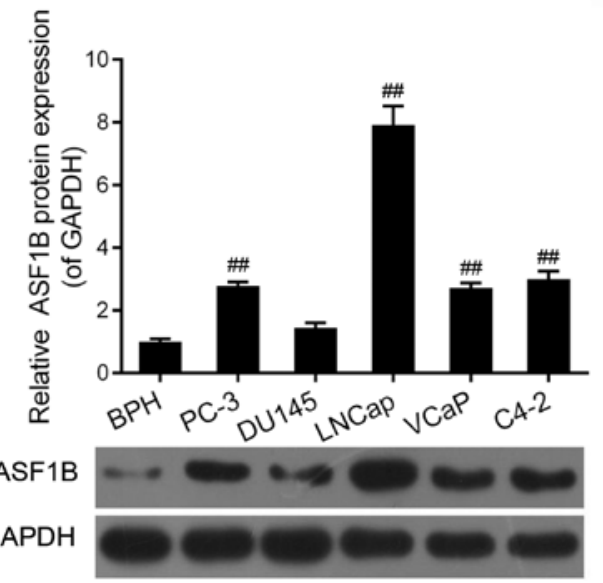

D

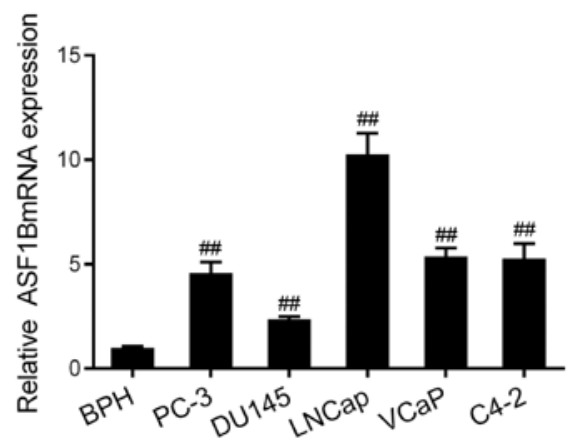

Figure 2. ASF1B is highly expressed in the prostate cancer tissues and cells. Between June 2015 and September 2017, 37 samples of prostate cancer tissues and adjacent tissues were obtained from patients with prostate cancer who were treated at the First Affiliated Hospital of Xinxiang Medical University. (A) Western blotting was performed to evaluate the protein expression of ASF1B in tissues (relative to the internal control, GAPDH). ${ }^{* *} \mathrm{P}<0.01$ vs. normal (healthy adjacent tissues). (B) RT-qPCR was used to detect the mRNA level of ASF1B in tissues. (C) The protein levels of ASF1B in BPH, PC-3, DU145, LNCap, VcaP and C4-2 were tested by western blotting (relative to the internal control, GAPDH). ${ }^{\#} \mathrm{P}<0.01 \mathrm{vs.} \mathrm{BPH}$. (D) The mRNA levels of ASF1B in BPH, PC-3, DU145, LNCap, $\mathrm{VcaP}$ and C4-2 were assessed by RT-qPCR. GAPDH was presented as sample control. ${ }^{\# /} \mathrm{P}<0.01 \mathrm{vs.} \mathrm{BPH}$. ASF1B, anti-silencing function $1 \mathrm{~B}$ histone chaperone; RT-qPCR, reverse transcription-quantitative polymerase chain reaction.

ASF1B in cancer tissues were significantly higher compared with that in healthy adjacent tissues (Fig. 2A; P<0.01). A total of six patients from the cohort were randomly selected to measure the protein expression of ASF1B. The results revealed that there was at least a 2-fold increase in the protein expression of ASF1B in cancer tissues compared with that in the healthy adjacent tissues (Fig. 2B; $\mathrm{P}<0.01$ ). Furthermore, the mRNA and protein levels of ASF1B in normal cells (BPH) were significantly lower compared with those in the $\mathrm{PCa}$ cells (PC-3, DU145, LNCap, VcaP and C4-2) (Fig. 2C and D;
$\mathrm{P}<0.01)$. The expression levels of ASF1B in LNCap and C4-2 cells were the highest compared with those in other cell lines. Hence, LNCap and C4-2 cells were selected for subsequent studies.

siASF1B decreases the viability of LNCap and C4-2 cells. The transfection efficiencies of the siRNA-ASF1B plasmid in LNCap and C4-2 cells were examined by RT-qPCR and western blotting. The results of the present study observed a significant decrease in ASF1B protein and mRNA expression 
A

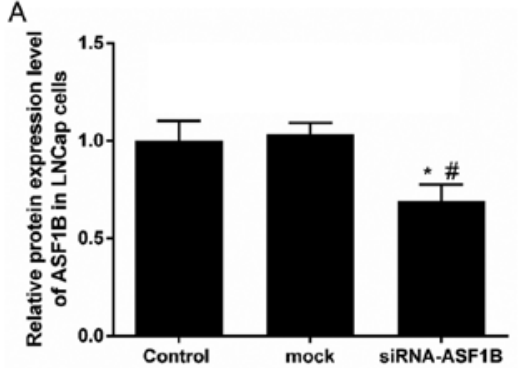

C

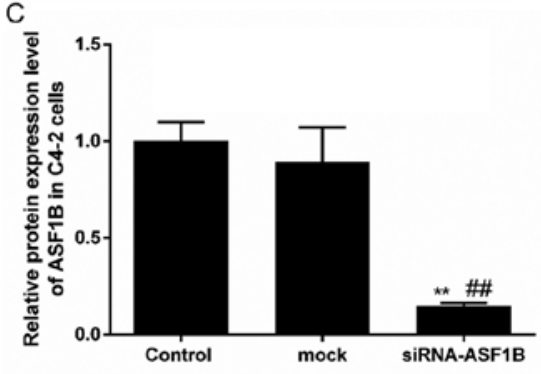

E

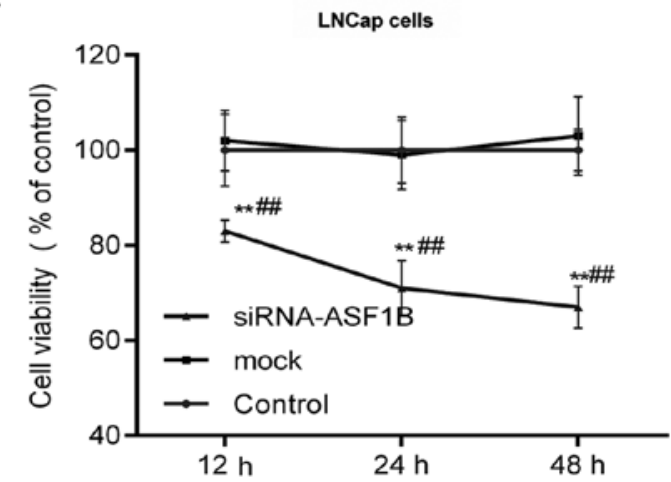

B

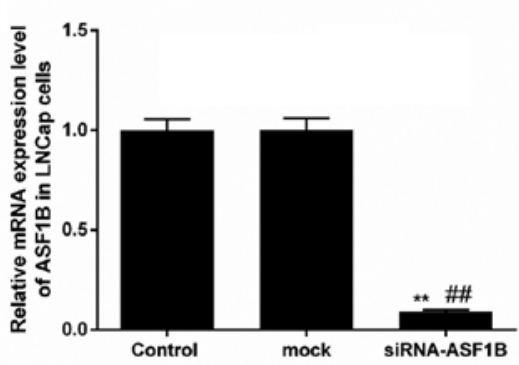

D

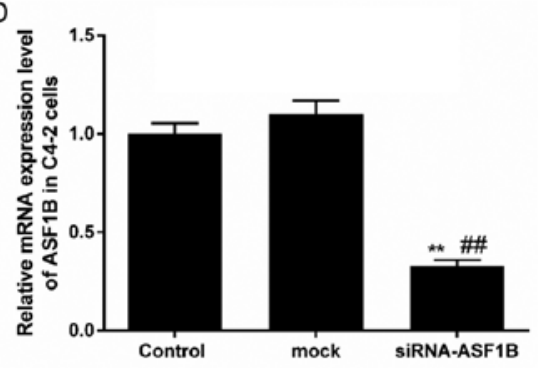

F

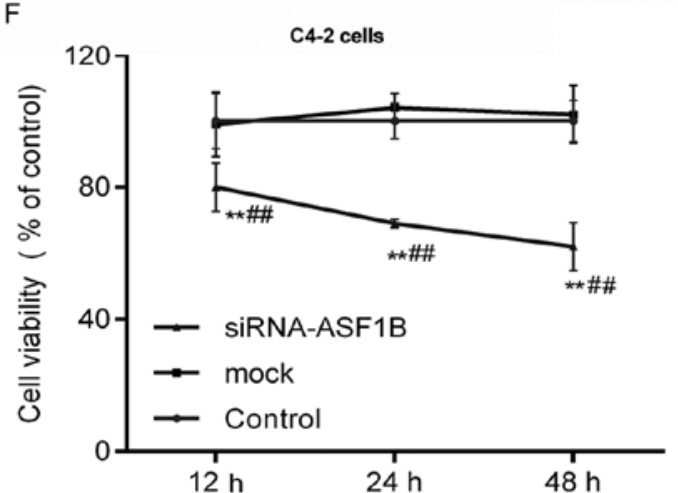

Figure 3. siASF1B decreases the viability of LNCap and C4-2 cells. (A-D) LNCap and C4-2 cells were transfected with ASF1B-target siRNA (siRNA-ASF1B) and unspecific scrambled siRNA (mock) plasmid. The (A) protein and (B) mRNA levels of ASF1B were detected using western blotting (relative to the internal control, GAPDH) and RT-qPCR in LNCap cells. (C) The protein and (D) mRNA levels of ASF1B were detected using western blotting (relative to the internal control, GAPDH) and RT-qPCR in C4-2 cells. LNCap and C4-2 cells were treated with PBS (control), unspecific scrambled siRNA plasmid (mock) and ASF1B-target siRNA (siRNA-ASF1B) for 12, 24 and $48 \mathrm{~h}$. A cell counting kit-8 was performed to examined the viabilities of LNCap (E) and C4-2 cells (F). ${ }^{*} \mathrm{P}<0.05 ;{ }^{* *} \mathrm{P}<0.01$ vs. control; ${ }^{\#} \mathrm{P}<0.05 ;{ }^{\# \#} \mathrm{P}<0.01$ vs. mock. ASF1B, anti-silencing function $1 \mathrm{~B}$ histone chaperone; RT-qPCR, reverse transcription-quantitative polymerase chain reaction; si, small inteferring RNA.

(Fig. 3A and $\mathrm{B} ; \mathrm{P}<0.05$ ) following the transfection of LNCap with the siRNA-ASF1B plasmid compared with the mock control group. Furthermore, the ASF1B protein and mRNA expression levels were reduced by siRNA-ASF1B transfection in $\mathrm{C} 4-2$ cells (Fig. 3C and $\mathrm{D} ; \mathrm{P}<0.05$ ).

The viabilities of LNCap and C4-2 cells were examined using a CCK-8 assay. The CCK-8 data demonstrated that the viabilities significantly decreased in siRNA-ASF1B-transfected LNCap and C4-2 cells compared with the mock (Fig. 3E and F; $\mathrm{P}<0.01$ ). Following transfection for $12 \mathrm{~h}$, cell viability was significantly decreased with si-ASF1B. Thus, the si-ASF1B transfection duration was set as $12 \mathrm{~h}$.

siASF1B induces apoptosis and arrests LNCap and C4-2 cells at the $G 1$ phase. The data in the present study revealed that compared with the mock control, siRNA-ASF1B significantly enhanced the apoptotic and promoted the cell cycle arrest of LNCap cells (Fig. 4A and B; $\mathrm{P}<0.01$ ). Additionally, when C4-2 cells were treated with siRNA-ASF1B, the apoptosis and the number of cells in G1 phase were significantly increased, whereas the number of cells in $\mathrm{G} 2$ and $\mathrm{S}$ phases was decreased significantly (Fig. 4C and D; P<0.01).

siASF1B inhibits the proliferation of LNCAp and C4-2 cells. In order to identify the effect of siASF1B on the proliferation of LNCap and C4-2 cells, colony formation analysis was performed. The results revealed that the colony formation of LNCap and C4-2 cells was significantly attenuated by siRNAASF1B transfection compared with the mock group (Fig. 5; $\mathrm{P}<0.01)$.

siASF $1 B$ regulates apoptosis-associated factors in LNCap and C4-2 cells. The results demonstrated that the protein and mRNA levels of cyclin D1 and Bcl-2 were downregulated; however, the protein and mRNA levels of p53, caspase-3 and Bax were upregulated in siRNA-ASF1B-transfected LNCap cells, compared with the mock group (Fig. 6A and B; $\mathrm{P}<0.01$ ). In addition, the protein and mRNA expression levels of these factors in C4-2 cells were in accordance with those observed in LNCap cells (Fig. 6C and D; $\mathrm{P}<0.01$ ). 

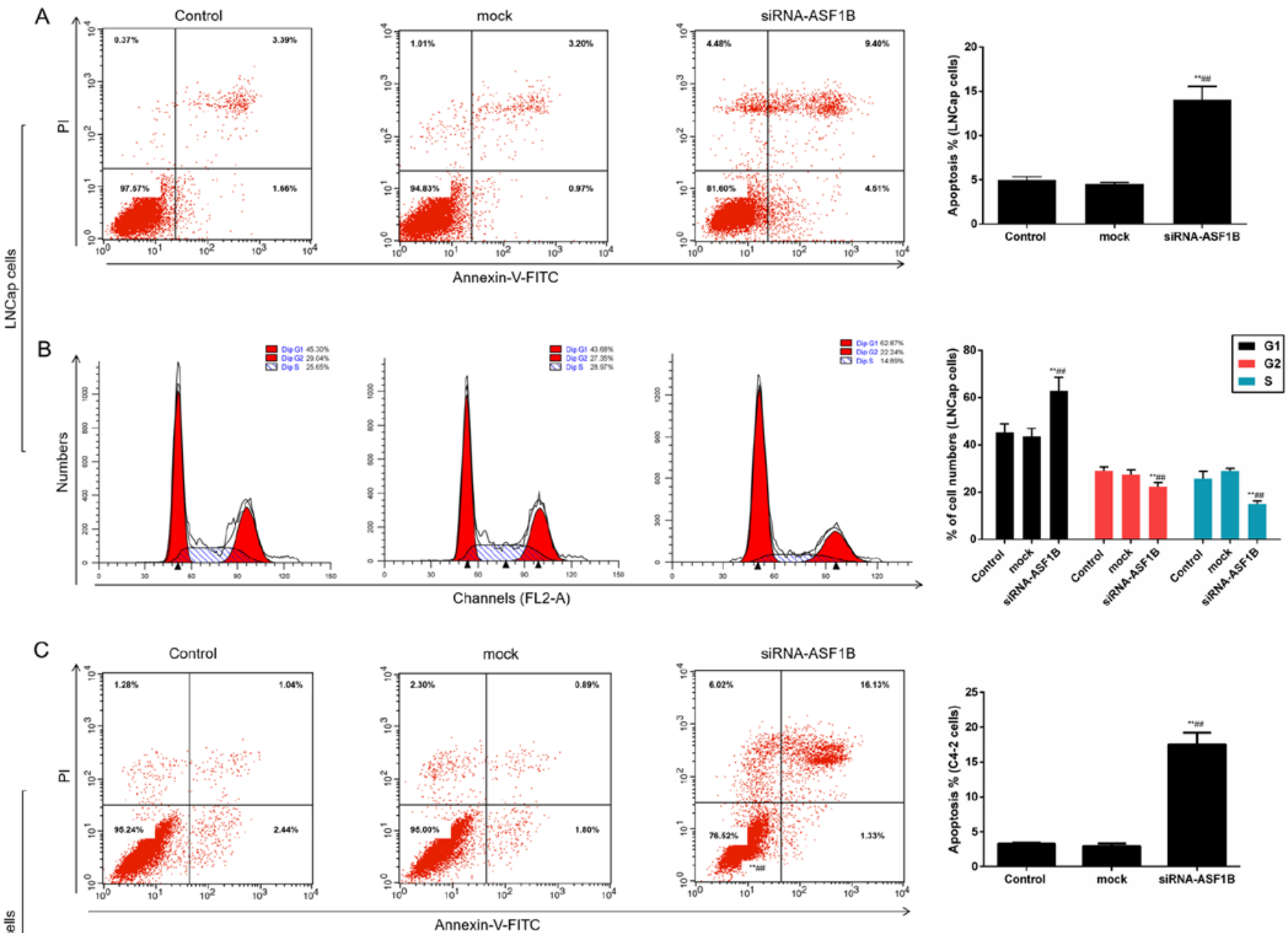

D
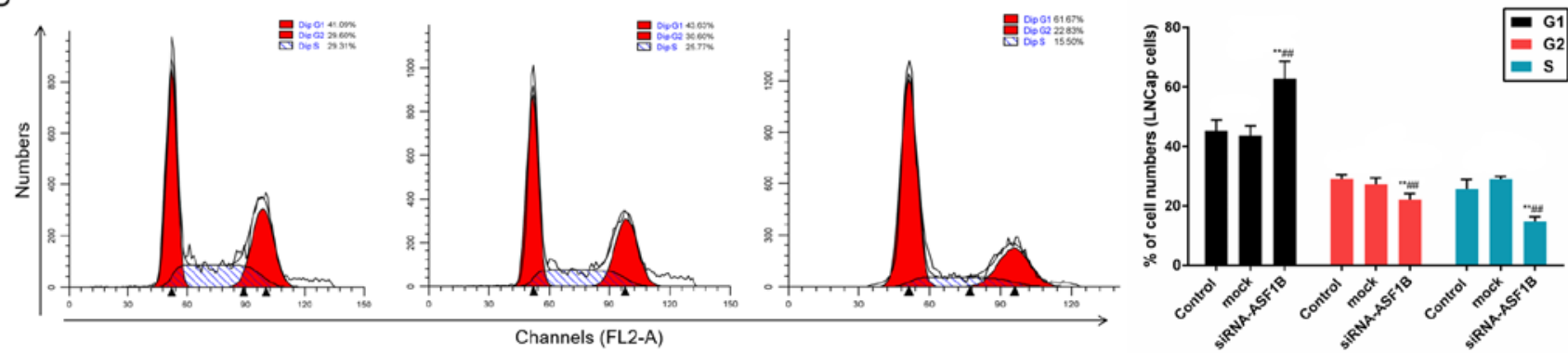

Figure 4. siASF1B induces apoptosis and arrests LNCap and C4-2 cells at the G1 phase. Annexin V-FITC/PI apoptosis detection kit was performed to identify the apoptosis of LNCap and C4-2 cells. PI dye kit was performed to determine the cell cycle distribution. (A) Cell apoptosis and (B) cell cycle analysis of LNCap cells. (C) Cell apoptosis and (D) cell cycle analysis of $\mathrm{C} 4-2$ cells. ${ }^{* *} \mathrm{P}<0.01$ vs. control; ${ }^{\# \#} \mathrm{P}<0.01$ vs. mock. ASF1B, anti-silencing function $1 \mathrm{~B}$ histone chaperone; si, small inteferring RNA; PI, propidium iodide.

siASFIB suppresses the PI3K/Akt signaling pathway in LNCap and C4-2 cells. In order to further explore the possible mechanism of siASF1B in LNCap and in C4-2 cells, western blotting was performed to detect the protein expression levels of p-PI3K, PI3K, p-Akt and Akt. Western blotting data demonstrated that siRNA-ASF1B significantly reduced the phosphorylation levels of PI3K and Akt in LNCap and C4-2 cells by at least a third compared with the mock control group. However, the levels of PI3K and Akt remained stable among other groups. The proportions of p-PI3K/PI3K and p-Akt/Akt in siRNA-ASF1B were significantly reduced compared with those in the mock group (Fig. 7; $\mathrm{P}<0.01$ ).

\section{Discussion}

In the present study, ASF1B was identified to be associated with cell cycle and cell differentiation in PCa. ASF1 was initially identified in yeast, and belongs to the histone $\mathrm{H} 3-\mathrm{H} 4$ chaperone protein. ASF1 regulates chromatin functions and has been demonstrated to contribute to tumorigenesis (27). ASF1 has two primary subtypes, which are ASF1A and ASF1B (28). Studies have reported that ASF1B is highly expressed in the human thymus and testicles (29). In addition, ASF1B has been reported to participate in the development of cervical and breast cancer $(30,31)$. However, the role of ASF1B 
Table III. Association between the expression levels of ASF1B and the clinicopathological features of patients with prostate cancer.

\begin{tabular}{|c|c|c|c|c|}
\hline Features & $\begin{array}{c}\text { Number of } \\
\text { patients }\end{array}$ & $\begin{array}{l}\text { Low ASF1B } \\
\text { expression }(\%)\end{array}$ & $\begin{array}{l}\text { High ASF1B } \\
\text { expression (\%) }\end{array}$ & P-value \\
\hline Age (years) & & & & 0.538 \\
\hline$<55$ & 16 & 10 (47.6) & $6(37.5)$ & \\
\hline$\geq 55$ & 21 & $11(52.4)$ & $10(62.5)$ & \\
\hline PSA (ng/ml) & & & & 0.942 \\
\hline$<4$ & 15 & $8(44.4)$ & $7(36.8)$ & \\
\hline$\geq 4$ & 22 & $10(55.6)$ & $12(63.2)$ & \\
\hline TNM stage & & & & $0.012 \mathrm{a}$ \\
\hline $\mathrm{I} / \mathrm{II}$ & 12 & $8(57.1)$ & $4(17.4)$ & \\
\hline $\mathrm{III} / \mathrm{IV}$ & 25 & $6(42.9)$ & $19(82.6)$ & \\
\hline Histological differentiation & & & & 0.060 \\
\hline Well & 3 & $2(12.5)$ & $1(4.7)$ & \\
\hline Moderate & 12 & $8(50.0)$ & $4(19)$ & \\
\hline Poor & 22 & $6(37.5)$ & $16(76.3)$ & \\
\hline Metastasis & & & & $0.010 \mathrm{a}$ \\
\hline No & 23 & 15 (83.3) & $8(42.1)$ & \\
\hline Yes & 14 & $3(16.7)$ & $11(57.9)$ & \\
\hline
\end{tabular}

${ }^{\mathrm{a}} \mathrm{P}<0.05$, Chi-square test. ASF1B, anti-silencing function 1B histone chaperone; PSA, prostate-specific antigen; TNM, tumor node metastasis classification of malignant tumors.
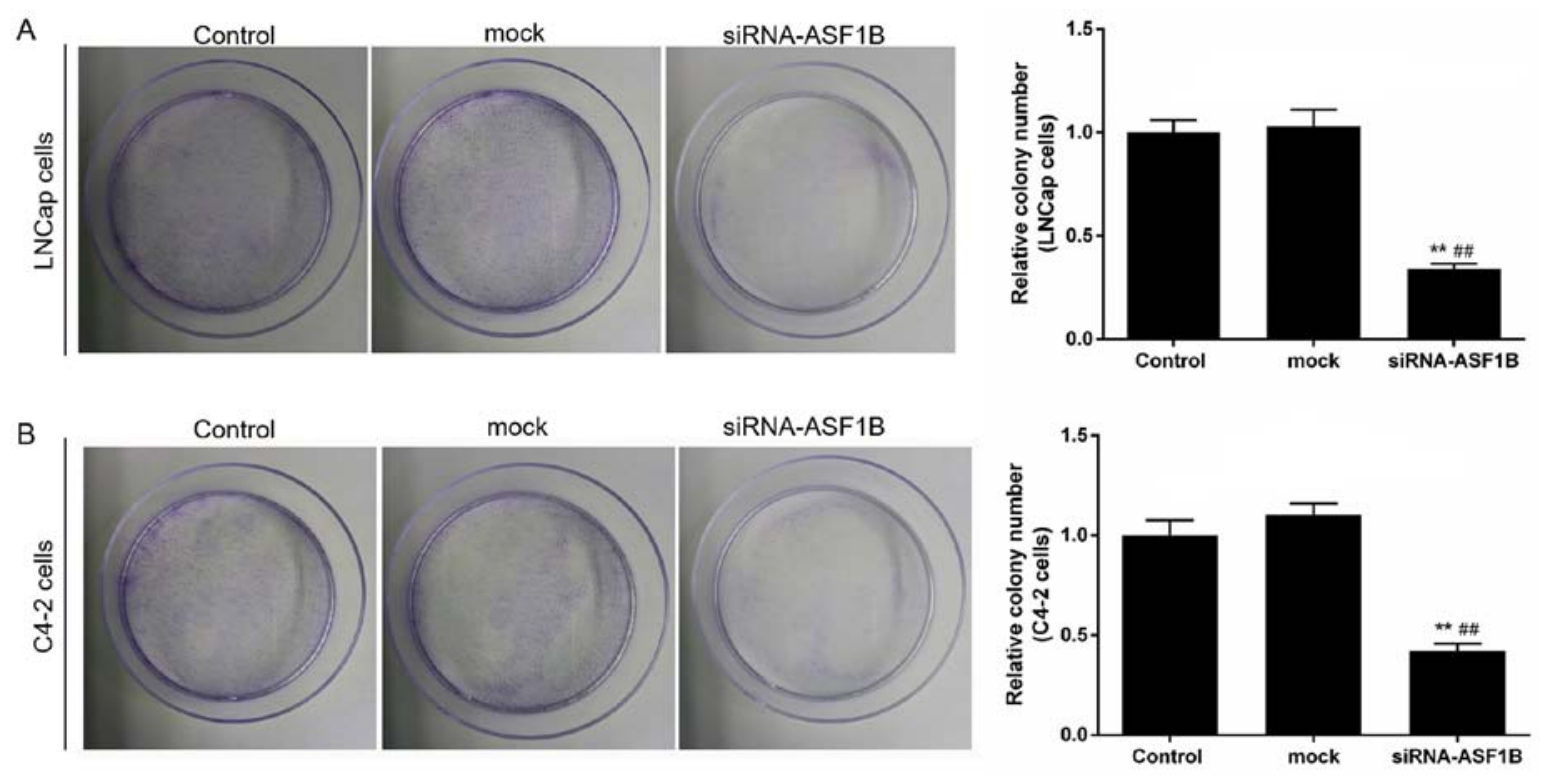

Figure 5. siASF1B inhibits the proliferation of LNCap and C4-2 cells. Crystal violet staining was used to examine the colony formation of (A) LNCap and (B) C4-2 cells Magnification, $\mathrm{x} 2.5 .{ }^{* *} \mathrm{P}<0.01$ vs. control; ${ }^{\# \#} \mathrm{P}<0.01$ vs. mock. ASF1B, anti-silencing function $1 \mathrm{~B}$ histone chaperone; si, small inteferring RNA.

in PCa remains unclear. Therefore, the present study aimed to explore the function of ASF1B in PCa.

The results revealed that ASF1B was highly expressed in PCa tissues and cells compared with healthy tissues and cells, respectively. This result is similar to the high expression of ASF1B identified in breast cancer and cervical carcinoma $(30,31)$. Furthermore, the results of the present study revealed that high expression of ASF1B was associated with a low overall survival rate, and that the expression of ASF1B was associated with TNM stage and metastasis.

A previous study has demonstrated that the overexpression of ASF1B markedly enhances the proliferation of breast cancer (30). Thus, we hypothesized that siASF1B may decrease the growth of PCa cells. The results also demonstrated that siRNA-ASF1B significantly decreased the viability and the colon formation of LNCap and C4-2 cells compared with 

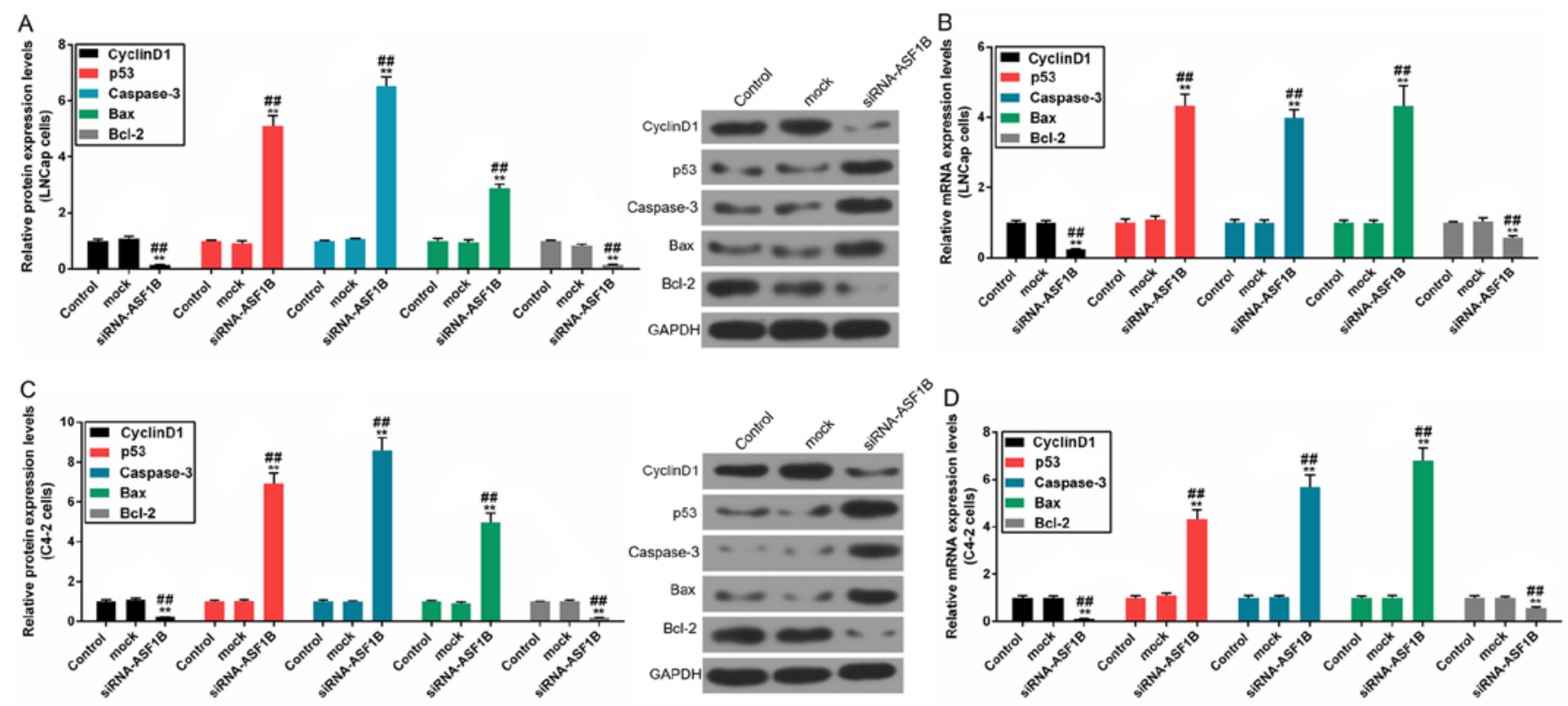

Figure 6. siASF1B regulates proliferation- and apoptosis-associated factors in LNCap and C4-2 cells. The protein and mRNA levels of p53, cyclin D1, caspase-3, Bax and Bcl-2 in LNCap and C4-2 cell were determined by western blotting (relative to the internal control, GAPDH) and reverse transcriptionquantitative polymerase chain reaction. The (A) protein and (B) mRNA levels of p53, cyclin D1, caspase-3, Bax and Bcl-2 in LNCap cells. The (C) protein and (D) mRNA levels of p53, cyclin D1, caspase-3, Bax and Bcl-2 in.C4-2 cells. ${ }^{* *} \mathrm{P}<0.01$ vs. control; ${ }^{* \#} \mathrm{P}<0.01$ vs. mock. ASF1B, anti-silencing function $1 \mathrm{~B}$ histone chaperone; si, small inteferring RNA; Bax, Bcl-2-associated X protein; Bcl-2, B-cell lymphoma 2.
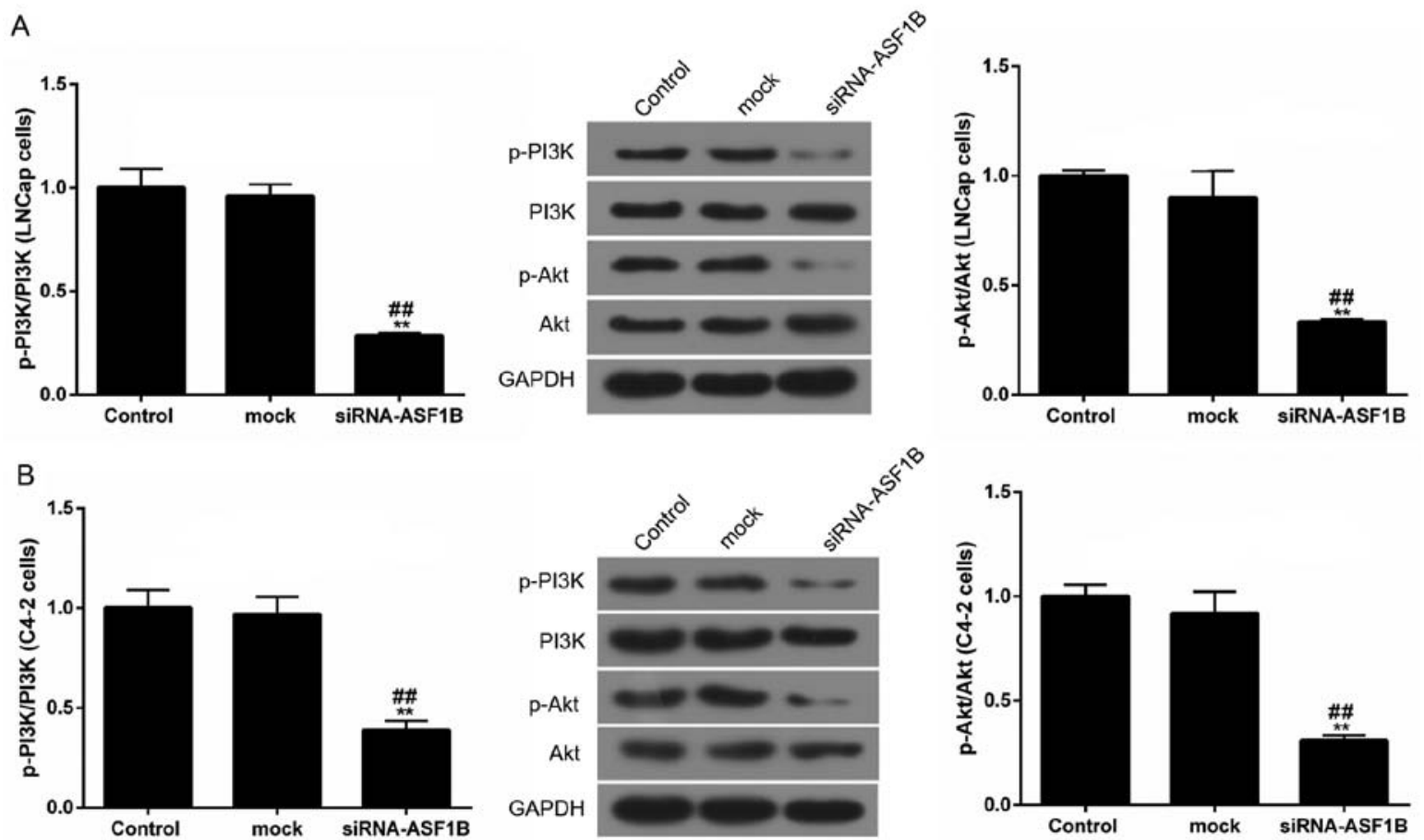

Figure 7. siASF1B suppresses the PI3K/Akt pathway in LNCap and C4-2 cells. The protein levels of p-PI3K, PI3K, p-Akt and Akt in (A) LNCap and (B) C4-2 cells were examined using western blotting (relative to the internal control, GAPDH). ${ }^{* *} \mathrm{P}<0.01$ vs. control; ${ }^{\# \#} \mathrm{P}<0.01$ vs. mock. ASF1B, anti-silencing function 1B histone chaperone; si, small inteferring RNA; PI3K, phosphatidylinositol 3 kinase; Akt, Protein kinase B; p, phosphorylated.

control cells. Cell proliferation is associated with cell cycle distribution. Changes in proliferation participate in the regulation of cell cycle phases, including G1, G2 and S (32,33). In the present study, the data revealed that siRNA-ASF1B induced G1 phase cell cycle arrest. Consistently, researches have also confirmed previously that various anti-genes promote G1 phase arrest and inhibit the cyclin D1 expression in cancer cells (34-37). Similarly, the present results indicated that siRNA-ASF1B inhibited the expression levels of cyclin D1 in LNCap and C4-2 cells suggesting that ASF1B silencing promotes cell cycle arrest of $\mathrm{PCa}$.

Apoptosis is another important process in the progression of tumors. Anticancer drugs and genes serve important roles in promoting the process of cancer apoptosis (38-40). 
Therefore, the effect of siASF1B on the apoptosis of PCa was analyzed. The results revealed that siRNA-ASF1B increased the apoptosis rate of LNCap and C4-2 cells. To further verify the inhibitory effect of siASF1B on apoptosis, factors associated with apoptosis were investigated. Bax and p53 are pro-apoptotic genes, and Bcl-2 is an anti-apoptotic gene $(41,42)$. Additionally, studies demonstrated that the activity of caspase- 3 is strengthened during the process of cell apoptosis (43-45). In the present study, siRNA-ASF1B significantly upregulated the levels of p53, cleaved caspase-3 and Bax. However, siRNA-ASF1B treatment significantly downregulated Bcl-2 expression. These results indicated that the knockdown of ASF1B accelerated the apoptosis of PCa cells by inhibiting Bcl-2 expression, and enhancing the expression levels of p53, caspase-3 and Bax. Consistently, ASF1B has been reported as a necessary factor for promoting cell proliferation in breast cancer (30). A previous study indicated that ASF1B may be a therapeutic target in cancer (46). Taken together, it was concluded that the downregulation of ASF1B exerted an antitumor effect on PCa by promoting cell apoptosis and cell cycle arrest.

The PI3K/Akt signaling pathway serves a role in cell growth and proliferation, and has been observed to be dysregulated in various cancer types (47). A previous study demonstrated that the PI3K/Akt signaling pathway is inactivated, whereas osthole promotes the apoptosis of esophageal squamous cell carcinoma (48). Furthermore, repression of the PI3K/Akt signaling pathway inhibits cell viability and may enhance the apoptosis of PCa (49), indicating the role of the PI3K/Akt signaling pathway during tumor progression. Thus, the expression of PI3K and Akt was determined in the present study in order to explore the role of the PI3K/Akt pathway in the antitumor effect of si-ASF1B. The data revealed that siRNA-ASF1B significantly reduced the phosphorylation levels of PI3K and Akt in LNCap and C4-2 cells, suggesting that the silencing of ASF1B decreased the activity of the signaling PI3K/Akt pathway in PCa. Thus, inhibition of the PI3K/Akt pathway may be a possible mechanism underlying the antitumor effect of si-ASF1B in PCa.

In conclusion, the results of the present study demonstrated that ASF1B was highly upregulated in PCa. ASF1B silencing significantly induced G1 phase arrest, promoted cell apoptosis, and inhibited colon formation in PCa cells. The inhibition of the PI3K/Akt signaling pathway may be a possible contributor to the production of antitumor effect of si-ASF1B. These results suggest that the depletion of ASF1B may inhibit the progression of $\mathrm{PCa}$ and may be a potential target in treating $\mathrm{PCa}$.

\section{Acknowledgements}

Not applicable.

\section{Funding}

No funding was received.

\section{Availability of data and materials}

The analyzed data sets generated during the study are available from the corresponding author on reasonable request.

\section{Authors' contributions}

GYH and XJZ wrote the manuscript. GYH, XJZ, PL, QFY, ZYL and QNY performed the experiments. GYH and XXW designed the study. XJZ, PL and XXW performed the data analysis. GYH, XJZ and XXW revised the manuscript. All authors reviewed the manuscript.

\section{Ethics approval and consent to participate}

All patients recruited to the present study provided written informed consent for the utilization of their tissue samples for clinical research. The project protocol was approved by the Ethics Committee of The First Affiliated Hospital of Xinxiang Medical University.

\section{Patient consent for publication}

Written informed consent was obtained from all participants for the publication of their data.

\section{Competing interests}

The authors declare that they have no competing interests.

\section{References}

1. Pérez-Rambla C, Puchades-Carrasco L, García-Flores M, RubioBriones J,López-Guerrero JA and Pineda-Lucena A: Non-invasive urinary metabolomic profiling discriminates prostate cancer from benign prostatic hyperplasia. Metabolomics 13: 52, 2017.

2. Bell KJ, Del Mar C, Wright G, Dickinson J and Glasziou P: Prevalence of incidental prostate cancer: A systematic review of autopsy studies. Int J Cancer 137: 1749-1757, 2015.

3. Hoffman KE, Chen MH, Moran BJ, Braccioforte MH, Dosoretz D, Salenius S, Katin MJ, Ross R and D'Amico AV: Prostate cancer-specific mortality and the extent of therapy in healthy elderly men with high-risk prostate cancer. Cancer 116 : 2590-2595, 2010.

4. Rim SH, Hall IJ, Massetti GM, Thomas CC, Li J and Richardson LC: Primary care providers' intended use of decision aids for prostate-specific antigen testing for prostate cancer screening. J Cancer Educ, 2018.

5. Shin H, Park YH, Kim YG, Lee JY and Park J: Aqueous two-phase system to isolate extracellular vesicles from urine for prostate cancer diagnosis. PLoS One 13: e0194818, 2018.

6. Li XX, Zhang YG, Wang D, Chen YF and Shan YH: Preventive effects of aspirin on cardiovascular complications in prostate cancer cases after endocrinotherapy. Asian Pac J Cancer Prev 16: 4909-4913, 2015

7. Liu Q, Tong D, Liu G, Yi Y, Xu J, Yang X, Wang L, Zhang J, Ye J, Zhang Y, et al: A novel BRCA2 mutation in prostate cancer sensitive to combined radiotherapy and androgen deprivation therapy. Cancer Biol Ther 19: 669-675, 2018.

8. Sheng MX, Wan LL, Liu CM,Liu CX and Chen SS: Cytoreductive cryosurgery in patients with bone metastatic prostate cancer: A retrospective analysis. Kaohsiung J Med Sci 33: 609-615, 2017.

9. Augello G, Balasus D, Fusilli C, Mazza T, Emma MR, Giannitrapani L, Agliastro R, Cervello M and Montalto G: Association between MICA gene variants and the risk of hepatitis $C$ virus-induced hepatocellular cancer in a sicilian population sample. OMICS 22: 274-282, 2018.

10. Concolino A, Olivo E, Tammè L, Fiumara CV, De Angelis MT, Quaresima B, Agosti V, Costanzo FS, Cuda G and Scumaci D: Proteomics analysis to assess the role of mitochondria in BRCA1mediated breast tumorigenesis. Proteomes 6: 6, 2018.

11. Xu Y, Zhang C, Liang H, Hu S, Li P, Liu L, Duan X, Chen C, Zhang Y and Dai P: Dishevelled 1, a pivotal positive regulator of the Wnt signalling pathway, mediates 5-fluorouracil resistance in HepG2 cells. Artif Cells Nanomed Biotechnol: Mar 27, 2018 (Epub ahead of print). doi: 10.1080/21691401.2018.1453827. 
12. Bohlen J, McLaughlin SL, Hazard-Jenkins H, Infante AM, Montgomery C, Davis M and Pistilli EE: Dysregulation of metabolic-associated pathways in muscle of breast cancer patients: Preclinical evaluation of interleukin-15 targeting fatigue. J Cachexia Sarcopenia Muscle, 2018.

13. Kalimuthu S, Zhu L, Oh JM, Lee HW, Gangadaran P, Rajendran RL, Baek SH, Jeon YH, Jeong SY, Lee SW, et al: Regulated mesenchymal stem cells mediated colon cancer therapy assessed by reporter gene based optical imaging. Int J Mol Sci 19: 19, 2018.

14. Liu H, Schreiber SL and Stockwell BR: Targeting dependency on the GPX4 lipid peroxide repair pathway for cancer therapy. Biochemistry 57: 2059-2060, 2018.

15. Tremblay-LeMay R, Rastgoo N and Chang H: Modulating PD-L1 expression in multiple myeloma: An alternative strategy to target the PD-1/PD-L1 pathway. J Hematol Oncol 11: 46, 2018.

16. Das SK, Pradhan AK, Bhoopathi P, Talukdar S, Shen XN, Sarkar D, Emdad L and Fisher PB: The MDA-9/Syntenin/ IGF-1R/STAT3 axis directs prostate cancer invasion. Cancer Res 78: 2852-2863, 2018.

17. Karbasforooshan H, Roohbakhsh A and Karimi G: SIRT1 and microRNAs: The role in breast, lung and prostate cancers. Exp Cell Res 367: 1-6, 2018

18. Li P, You S, Nguyen C, Wang Y, Kim J, Sirohi D, Ziembiec A, Luthringer D, Lin SC, Daskivich T, et al: Genes involved in prostate cancer progression determine MRI visibility. Theranostics 8: 1752-1765, 2018.

19. Sehrawat A, Gao L, Wang Y, Bankhead A III, McWeeney SK, King CJ, Schwartzman J, Urrutia J, Bisson WH, Coleman DJ, et al: LSD1 activates a lethal prostate cancer gene network independently of its demethylase function. Proc Natl Acad Sci USA 115: E4179-E4188, 2018.

20. Brufsky AM and Dickler MN: Estrogen receptor-positive breast cancer: Exploiting signaling pathways implicated in endocrine resistance. Oncologist 23: 528-539, 2018.

21. Mohammadi A, Amooeian VG and Rashidi E: Dysfunction in brain-derived neurotrophic factor signaling pathway and susceptibility to schizophrenia, Parkinson's and Alzheimer's diseases. Curr Gene Ther 18: 45-63, 2018.

22. Danielsen SA, Eide PW, Nesbakken A, Guren T, Leithe E and Lothe RA: Portrait of the PI3K/AKT pathway in colorectal cancer. Biochim Biophys Acta 1855: 104-121, 2015.

23. Toren $\mathrm{P}$ and Zoubeidi A: Targeting the PI3K/Akt pathway in prostate cancer: Challenges and opportunities (Review). Int J Oncol 45: 1793-1801, 2014

24. Liu ST, Hui G, Mathis C, Chamie K, Pantuck AJ and Drakaki A The current status and future role of the phosphoinositide 3 kinase/ AKT signaling pathway in urothelial cancer: An old pathway in the new immunotherapy era. Clin Genitourin Cancer 16: e269-e276, 2018.

25. Pompura SL and Dominguez-Villar M: The PI3K/AKT signaling pathway in regulatory T-cell development, stability, and function. J Leukoc Biol 103: 1065-1076, 2018.

26. Ramakrishnan V and Kumar S: PI3K/AKT/mTOR pathway in multiple myeloma: From basic biology to clinical promise. Leuk Lymphoma: Jan 11, 2018 (Epub ahead of print). doi: 10.1080/104 28194.2017.1421760

27. Seol JH, Song TY, Oh SE, Jo C, Choi A, Kim B, Park J, Hong S, Song I, Jung KY, et al: Identification of small molecules that inhibit the histone chaperone Asf 1 and its chromatin function. BMB Rep 48: 685-690, 2015

28. De Koning L, Corpet A, Haber JE and Almouzni G: Histone chaperones: An escort network regulating histone traffic. Nat Struct Mol Biol 14: 997-1007, 2007.

29. Umehara T and Horikoshi M: Transcription initiation factor IID-interactive histone chaperone CIA-II implicated in mammalian spermatogenesis. J Biol Chem 278: 35660-35667, 2003

30. Corpet A, De Koning L, Toedling J, Savignoni A, Berger F, Lemaître C, O'Sullivan RJ, Karlseder J, Barillot E, Asselain B, et al: Asf1b, the necessary Asf1 isoform for proliferation, is predictive of outcome in breast cancer. EMBO J 30: 480-493, 2011.

31. Rosty C, Sheffer M, Tsafrir D, Stransky N, Tsafrir I, Peter M, de Crémoux $\mathrm{P}$, de La Rochefordière A, Salmon R, Dorval T, et al: Identification of a proliferation gene cluster associated with HPV E6/E7 expression level and viral DNA load in invasive cervical carcinoma. Oncogene 24: 7094-7104, 2005.

32. Mens MMJ and Ghanbari M: Cell cycle regulation of stem cells by MicroRNAs. Stem Cell Rev 14: 309-322, 2018.
33. Uzquiano A, Gladwyn-Ng I, Nguyen L, Reiner O, Götz M, MatsuzakiFandFrancis F: Cortical progenitor biology: Key features mediating proliferation versus differentiation. J Neurochem: Mar 23, 2018 (Epub ahead of print). doi: 10.1111/jnc.14338

34. Jiang H, Zhu Y, Zhou Z, Xu J, Jin S, Xu K, Zhang H, Sun Q, Wang $\mathrm{J}$ and $\mathrm{Xu}$ J: PRMT5 promotes cell proliferation by inhibiting BTG2 expression via the ERK signaling pathway in hepatocellular carcinoma. Cancer Med 7: 869-882, 2018.

35. Leem DG, Shin JS, Kim KT, Choi SY, Lee MH and Lee KT: Dammarane-type triterpene ginsenoside-Rg18 inhibits human non-small cell lung cancer A549 cell proliferation via G1 phase arrest. Oncol Lett 15: 6043-6049, 2018.

36. Yue Y, Yuan Y, Li L, Fan J, Li C, Peng W and Ren G: Homeobox protein MSX1 inhibits the growth and metastasis of breast cancer cells and is frequently silenced by promoter methylation. Int J Mol Med 41: 2986-2996, 2018.

37. Zhang Y, Chen S, Wei C, Rankin GO, Rojanasakul Y, Ren N, Ye X and Chen YC: Dietary compound proanthocyanidins from Chinese bayberry (Myrica rubra Sieb. et Zucc.) leaves inhibit angiogenesis and regulate cell cycle of cisplatin-resistant ovarian cancer cells via targeting Akt pathway. J Funct Foods 40: 573-581, 2018.

38. Lin CL, Lee $\mathrm{CH}$, Chen CM, Cheng CW, Chen PN, Ying TH and Hsieh $\mathrm{YH}$ : Protodioscin induces apoptosis through ROS-mediated endoplasmic reticulum stress via the JNK/p38 activation pathways in human cervical cancer cells. Cell Physio Biochem 46: 322-334, 2018.

39. Park CH, Han SE, Nam-Goong IS, Kim YI and Kim ES: Combined effects of Baicalein and Docetaxel on apoptosis in $8505 \mathrm{c}$ anaplastic thyroid cancer cells via downregulation of the ERK and Akt/mTOR pathways. Endocrinol Metab (Seoul) 33: 121-132, 2018.

40. Torres RG, Casanova L, Carvalho J, Marcondes MC, Costa SS, Sola-Penna M and Zancan P: Ocimum basilicum but not Ocimum gratissimum present cytotoxic effects on human breast cancer cell line MCF-7, inducing apoptosis and triggering mTOR/Akt/ p70S6K pathway. J Bioenerg Biomembr 50: 93-105, 2018.

41. Beberok A, Wrześniok D, Rok J, Rzepka Z, Respondek M and Buszman E: Ciprofloxacin triggers the apoptosis of human triplenegative breast cancer MDA-MB-231 cells via the p53/Bax/ Bcl-2 signaling pathway. Int J Oncol: Mar 8, 2018 (Epub ahead of print). doi: 10.3892/ijo.2018.4310.

42. Mirakhor Samani S, Ezazi Bojnordi T, Zarghampour M, Merat S and Fouladi DF: Expression of p53, Bcl-2 and Bax in endometrial carcinoma, endometrial hyperplasia and normal endometrium: A histopathological study. J Obstet Gynaecol: Mar 21, 2018 (Epub ahead of print). doi: 10.1080/01443615.2018.1437717.

43. Alotaibi MR, Hassan ZK, Al-Rejaie SS, Alshammari MA, Almutairi MM, Alhoshani AR, Alanazi WA, Hafez MM and Al-Shabanah OA: Characterization of apoptosis in a breast cancer cell line after IL-10 silencing. Asian Pac J Cancer Prev 19: 777-783, 2018.

44. Hu M, Li F and Wang W: Vitexin protects dopaminergic neurons in MPTP-induced Parkinson's disease through PI3K/Akt signaling pathway. Drug Des Devel Ther 12: 565-573, 2018.

45. Tsai TC, Lai KH, Su JH, Wu YJ and Sheu JH: 7-Acetylsinumaximol B induces apoptosis and autophagy in human gastric carcinoma cells through mitochondria dysfunction and activation of the PERK/eIF2 $\alpha / \mathrm{ATF} 4 / \mathrm{CHOP}$ signaling pathway. Mar Drugs 16: E104, 2018.

46. Almouzni G and Corpet A: Asf $1 \mathrm{~b}$ as a prognosis marker and therapeutic target in human cancer. US 2013/0149320 A1. Filed May 31, 2011; issued June 13, 2013.

47. Davis WJ, Lehmann PZ and Li W: Nuclear PI3K signaling in cell growth and tumorigenesis. Front Cell Dev Biol 3: 24, 2015.

48. Zhu X, Li Z, Li T, Long F, Lv Y, Liu L, Liu X and Zhan Q: Osthole inhibits the PI3K/AKT signaling pathway via activation of PTEN and induces cell cycle arrest and apoptosis in esophageal squamous cell carcinoma. Biomed Pharmacother 102: 502-509, 2018.

49. Wu Z, Zhu Q, Yin Y, Kang D, Cao R, Tian Q, Zhang Y, Lu S and Liu P: Traditional Chinese Medicine CFF-1 induced cell growth inhibition, autophagy, and apoptosis via inhibiting EGFR-related pathways in prostate cancer. Cancer Med 7: 1546-1559, 2018.

This work is licensed under a Creative Commons Attribution-NonCommercial-NoDerivatives 4.0 International (CC BY-NC-ND 4.0) License. 